\title{
Knowledge management in cyberphysical systems: determining the quality requirements for health systems with the Kano model
}

\author{
Davide Di Fatta* \\ Department of SEAS, \\ University of Palermo, Italy \\ Email: difatta.davide@gmail.com \\ *Corresponding author

\section{Vasja Roblek}

Higher Institution Fizioterapevtika, Bogatajeva ulica 15, Medvode, Slovenia

Email: vasja.roblek@gmail.com

\section{Gandolfo Dominici}

\author{
Department of SEAS, \\ University of Palermo, Italy \\ and \\ Business Systems Laboratory, \\ Avellino, Italy \\ Email: gandolfo.dominici@unipa.it
}

\begin{abstract}
This paper focuses on knowledge management in cyberphysical systems (CPS), dealing with the importance and influence of smart technologies for the creation of the smart health systems as a part of the smart home. This approach considers the reorganisation and adaptation of medicine and health systems, building the research framework upon knowledge management 4.0 for health systems. Customer satisfaction or dissatisfaction was researched using the qualitative methodology of the Kano model. The questionnaire deals with five factors that play a crucial role in the decision to purchase such a system: 1) software reliability; 2) medical device interoperability; 3) security and privacy; 4) system feedback; 5) architecture. The results show that attractive requirements, such as architecture and medical device interoperability, have high values for customer satisfaction and low scores for customer dissatisfaction.
\end{abstract}

Keywords: knowledge management; health systems; cyberphysical systems; CPS; Kano model.

Reference to this paper should be made as follows: Di Fatta, D., Roblek, V. and Dominici, G. (2018) 'Knowledge management in cyberphysical systems: determining the quality requirements for health systems with the Kano model', Int. J. Markets and Business Systems, Vol. 3, No. 2, pp.163-180. 
Biographical notes: Davide Di Fatta holds a $\mathrm{PhD}$ in Economics and Management from the University of Messina (Italy). He currently collaborates with the SEAS Department at the University of Palermo (Italy). His main research field are web marketing, focusing on e-commerce and conversion rate optimisation; system thinking and (cultural) agency theory. He is the Associate Editor for IJEMR and IJMABS. He is also member of the advisory board for many other international journals (Kybernetes and IJMS) and academic organisations (Business Systems Laboratory).

Vasja Roblek is an independent researcher. He is cooperating on scientific research work within NGO Business Systems Laboratory. His current research areas are digital economy, knowledge management, organisational changes and sustainable development.

Gandolfo Dominici is a tenured Associate Professor of Marketing at the Department SEAS of the University of Palermo, Italy. He is the Scientific Director and a co-Founder of the Business Systems Laboratory. $\mathrm{He}$ is a member of directors' board of the World Organisation for Systems and Cybernetics (WOSC), Chair of the Special Integration Group 'Systems Applications in Business and Industry' for the International Society for the Systems Sciences (ISSS). He is the author of more than 70 published articles and books. His main research interests are marketing, e-marketing, new product development, systems thinking and organisational cybernetics.

\section{Introduction: driving forces for establishing cyberphysical health systems}

Cyberphysical systems (CPS) have gained momentum in recent years, emerging as a new area of next-generation engineered systems (Gunes et al., 2014).

Although numerous definitions have been put forward from different perspectives (Lee, 2008; Rajkumar et al., 2010; Marwedel, 2010; Gill, 2010), CPS can be considered "complex, multi-disciplinary, physically-aware next generation engineered systems that integrate embedded computing technology (cyber part) into the physical phenomena by using transformative research approaches. This integration mainly includes observation, communication and control aspects of the physical systems from the multi-disciplinary perspective [Gunes et al., (2014), p.4244]." A CPS is thus made up of the physical world, interfaces, and cybersystems. Specifically, the physical world is represented by the physical phenomena that it is to control and monitor. The interfaces include the communication network and other intermediate components, such as interconnected sensors, actuators, analogue-to-digital converters, and digital-to-analogue converters, responsible for linking the cybersystems to the physical world. Finally, cybersystems lead to the next generation of embedded devices, which process information and communicate with their different distributed environment (Gunes et al., 2014). Effectively, a CPS is directed to integrate "physical devices, such as sensors and cameras (CCTV), with cyber components to form an analytical system that responds intelligently to dynamic changes in the real-world scenarios (Haque et al., 2014).”

Enabling the physical world to merge with the virtual, leading to an IoT system of data and services, it is possible to gain advantages linked to the CPS. These advantages 
include strong interactions between humans and the system; network integration; autonomy; flexibility; faster response time; optimisation; better performance; and the ability to deal with certainty (Haque et al., 2014). Due to these heterogeneous advantages, CPS is applied in different research and practical contexts, such as manufacturing, air transportation, critical infrastructure, advanced automotive systems, environmental control, electronics, intelligence transportation, energy control, assisted living, defense systems, and healthcare and medicine (see Table 1).

Table 1 Sample applications of CPS

\begin{tabular}{|c|c|}
\hline Manufacturing & $\begin{array}{l}\text { Smart production equipment, processes, automation, control, and networks; } \\
\text { new product design }\end{array}$ \\
\hline Infrastructure & Intelligent vehicles and traffic control, intelligent structures and pavements \\
\hline $\begin{array}{l}\text { Emergency } \\
\text { response }\end{array}$ & $\begin{array}{c}\text { Detection and surveillance systems, communication networks, and emergency } \\
\text { response equipment }\end{array}$ \\
\hline Defense & Soldier equipment systems, weapons systems, systems of systems, logistics \\
\hline Healthcare & Body area networks and assistive systems \\
\hline
\end{tabular}

Source: Executive roundtable on Cyberphysical Systems (2013)

CPS assumes a critical role in this last context as it permits the acquisition of medical data via suitable sensors for real-time processing and evaluation, thus making it possible to provide individual medical treatment to patients with long-term illnesses. In a smart health system, individual medical requirements can be taken into account and an increasing number of people can be better supported, assisted, and cared for. Additionally, it allows extensive medical treatment without restricting independence in a person's living situation; better support and primary care in medical emergencies; high-performance solutions in telemedicine and remote medical diagnosis; and more extensive consultation and support in medical issues than pure information forums.

The development and distribution of cyber physical health systems has been stimulated mainly by three converging drivers:

a medical sensors

b wireless sensor networks (WSNs)

c cloud computing (Haque et al., 2014).

Medical sensors are capable of gathering a large set of patient vital information, including health data. These data are sent to a gateway through wireless communication, and can then be stored in an appropriate server and made easily accessible to clinicians. However, the networks of wireless sensors used to gather patient data are constrained in terms of processing, energy, and storage capacity. These sensors also have a limited capacity to store large amount of data and scarce resources for processing data (Haque et al., 2014). Cloud computing can provide adequate solutions to some of these questions. These are computing infrastructure systems that can be accessed at any time and from any location in the world; hence, cloud computing can be seen as a service system that offers computing, storage, networking, and software 'as a service' (Haque et al., 2014). 


\section{Literature review}

This section is organised as follows: Section 2.1 deals with the process of reorganisation and adaptation of medicine and health systems; Section 2.2 describes the implementation of the healthcare IoT.

\subsection{The process of reorganisation and adaptation of medicine and health systems}

The first digitalisation in national health systems arrived over the last ten years, with most investment in e-health programs. This generally involved for the digitalisation of the medical administration (e.g., medical telecare and prescriptions). The modest returns include higher care quality and better patient outcomes. In practice, several national health systems (e.g., the UK and Slovenia) have had significant cost overruns and delays with implementing such e-health projects. The problem is that information technology support for clinical professionals is beyond the core mission of healthcare systems, which are often also incompatible with laws that prevent data integration (Aue et al., 2016; Sedlar et al., 2015).

\subsubsection{The rise of smart technologies in the human environment}

The so-called industry 4.0 is a concept of economic policy that transforms the classical manufacturing and service systems (Mosconi, 2015; Di Fatta et al., 2016). New technologies, such as CPS, the internet of things (IoT), and the internet of services (IoS) are penetrating into the medicine and healthcare systems (Yolles and Di Fatta, 2017a, 2017 b). Industry 4.0 technologies are based on continuous communication over the internet, allowing continuous interaction and exchange of information, not only between humans $(\mathrm{C} 2 \mathrm{C})$ and between humans and machines $(\mathrm{C} 2 \mathrm{M})$, but also between the machines themselves (M2M) (Cooper and James, 2009).

Why involve health smart technology solutions to support urgent medicine? An answer to this question can be found in the major demographic change that the European Union is facing: aging of society. In 2013, 18\% of Europeans were aged 65 or more, and it is predicted that this number will be rise to $30 \%$ by 2060 (Davis, 2014).

Not only do older people have more health problems but, in affluent societies, we can also see a growing number of people affected by chronic health problems (such as diabetes, unbalanced blood pressure, and cardiovascular disease). As a result, more and more people need at least monitoring, and often even home or institution care. Social policy has to bear in mind that older people do not want to be socially isolated or to be dependent on other for self-care tasks. They would much rather stay at home than be hospitalised when they need specialised care. New IoT technologies can serve as a support instrument for nursing teams in such situations (Victor, 2013).

Gerontechnology combines gerontology with technology, and was developed as an interdisciplinary field of science responsible for implementing smart technologies in living environments to insure the independence and social participation of older people, with the aim of preventing, delaying, or compensating for the perceptual, cognitive, and physical declines that occur in aging (Calenti-Millan and Maseda, 2011). 


\subsubsection{Definition of a smart home}

The development and availability of 'smart technologies' is increasing our general well-being. Today, smart homes allow users to increase their living and working comfort, with increased safely and at a lower cost of use and maintenance. Smart homes also allow the use of wired or wireless communications; the integration of computers, telephones, and the internet, and control from one location. Smart homes therefore make life easier, increase comfort and safety, and save energy (Luor et al., 2015).

A smart home can incorporate the smart healthcare function (e.g., home-based healthcare network) alongside other important functions, such as home entertainment, home security, and home automation (Figure 1: Chan et al., 2009; Roblek et al., 2016).

In the case of a smart home system, healthcare can be integrated using embedded computers, and networks can monitor and control the physical processes, with feedback loops where physical processes affect computations, and vice versa. All information can be stored in the cloud and digital health companies will enable the exchange of health data (Möller, 2016).

The concept of smart home healthcare enables sick people to remain home while continuing to living a quality life. Such a digital healthcare platform does not only lead to organisational changes in health services, but also lowers cost of such services. A McKinsey research projects has shown that the implementation of patient self-service using digital channels instead of a direct visit to a physician, as well as patient self-management solutions, can produce net economic benefits of $7 \%$ to $11 \%$ of total healthcare spending (Aue et al., 2016).

Figure 1 Types of smart home functions (see online version for colours)

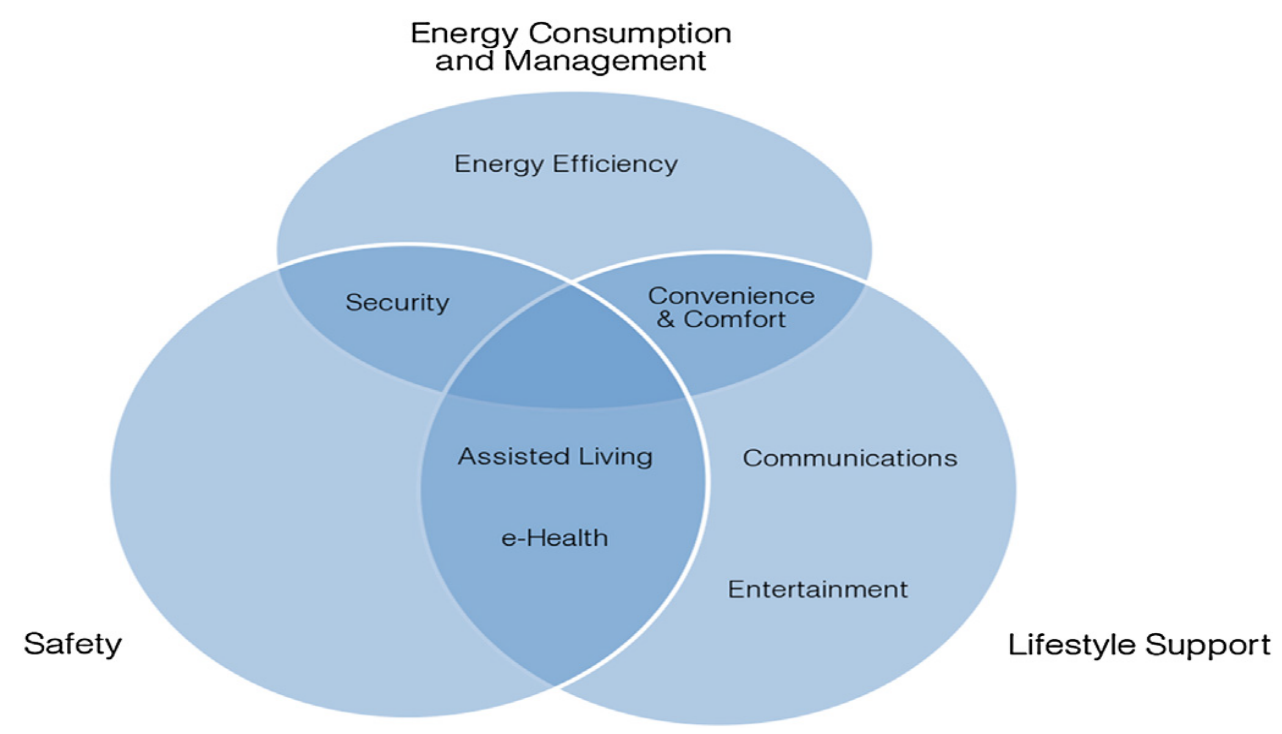

Source: Authors adaptation according to Balta-Ozkan et al. (2014).

As a typical case, consider the monitoring of vital human functions to allow urgent healthcare through mobile applications, sensors in clothing, sensors and surveillance cameras in houses (integrated into the building or into a smart phone application), 
monitoring the patient and sending information to doctors (Roblek et al., 2016; Pang et al., 2015; Figure 2).

Integration and information sharing are the key concepts of the smart health home. The characteristics of knowledge management 4.0 (Dominici et al., 2016; Roblek et al., 2016) are defined as:

- big data acquired directly from objects and users, and analysed and saved in the cloud

- information shared in real-time, content available online; no limitations on sharing information between people or things; in the case of personal data, it is necessary to restrict access to authorised people, and privacy and strong data protection should be provided

- information sharing and collaboration via wireless communications between people, between people and objects, and between objects.

Figure 2 Model of the process of knowledge management 4.0 in health management systems

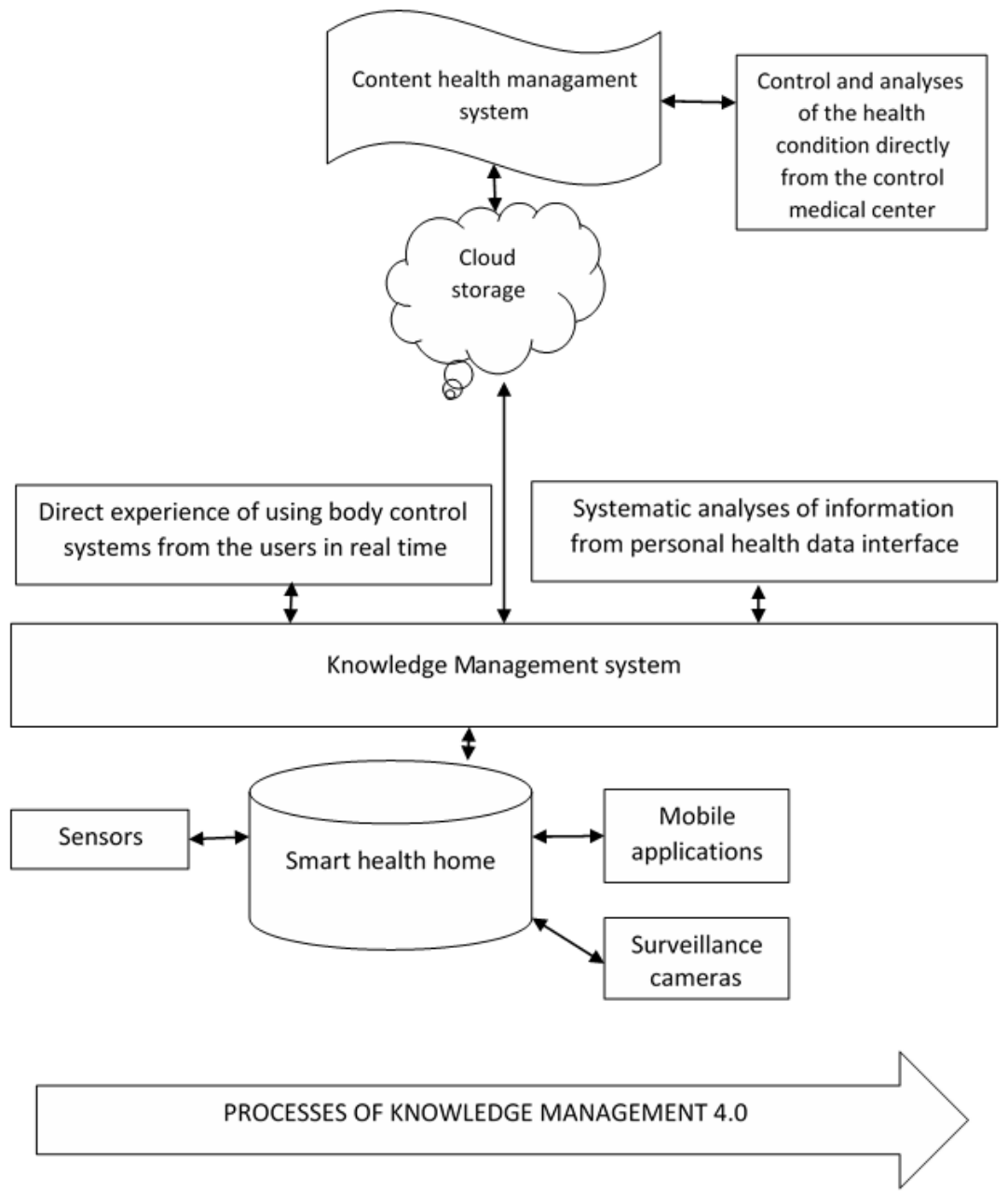


Figure 2 shows how smart technology may transform medicine and the healthcare system. Data-driven approaches can help to prepare health profiles and predictive models for individual patients. Hence, big data can provide medical information in real-time, allowing physicians to give more accurate better diagnoses and better treatment.

Smart technologies in the IoTs have received growing attention (Toledo Parra et al., 2017). The latest wireless communication standards in IoT are designed primarily for the transfer of sensor measurements from remote battery-powered sensors. They support services and allow the separation of network design of the sensors and the control systems. This is similar to the concept of mobile networks, where the phone users are not responsible for maintaining the network (Di Fatta et al., 2017), but the network operator services the telephony and data transmission. It is important that sensors remain for the majority of the time in a sleep, which is a state of low power consumption, while transmitting data mainly towards the network (main task sensors), but also being capable of two-way communication.

A real-time operating system (OS) provides an overview of the development and implementation of individual tasks, and since the tasks are fixed, is a very stable platform. Real-time OS-based systems are often used in applications that need to perform multiple tasks requiring high reliability and predictability of performance.

\subsection{Implementation of the healthcare IoT}

The implementation of the IoT in healthcare systems depends on the transformation speed of the healthcare systems, on the investment of IT companies in this sector, and on the openness of customers to adopting and trusting the new healthcare delivery model. These factors could lead to the reorganisation from the actual hospital-centric model towards a hospital-home balanced model, and finally towards the home-centric healthcare model that is expected to be implemented in the next 15 years (Man et al., 2015).

The healthcare management system needs to take into account the fact that the adoption of digitalisation and big data in medicine is pushing healthcare organisations to develop and invest in smart health technological solutions. The development of mobile applications that use mobile devices to monitor human functions is no longer sufficient. It is necessary to develop software to manage big data, in order to facilitate the transfer of health status with regard to specific groups of patients.

How can health systems provide smart global connectivity? The answer to this question might lie in promoting the development of new digital-health companies. The main characteristics of such companies must be that they have integrated innovation in their DNA. For the development of such companies, financing from health insurance alone will not be enough. It will be necessary to ask who will pay for the digitalisation of the health service and application development? The solution may lie in the development of national open innovation platforms that should be financed and steered by national health systems. Such platforms must hold healthcare data and standardised claims records, and provide data access for application programming interfaces, as well as common technical IT services, such as identity, access, and consent management. Open innovation platform need to be able to support healthcare systems to decrease costs. In accordance with the intention of the development platform, the stakeholders must define the distribution of the benefits (Aue et al., 2016). 
The IoT play an important role in reshaping the healthcare industry from a supply-oriented model to a demand-oriented one. In the classical healthcare system, patients (consumers) do not have control and have little or no information about the cost and quality of care. The new business model should thus allow customers to pursue perceived value and to seek resources for taking control over their own health.

The success of the new healthcare delivery model depends on combinations of the following factors, based on the integrated virtual cycle of innovations (Figure 3):

Self-health control and assessment of the health condition: the patient (customer) is updated on his or her health condition in real-time. To establishment the IoT, technology companies could set up a circuit between the customer and smart healthcare medical teams through

1 radio frequency identification (RFID)

2 WSNs

3 middleware

4 cloud computing

5 IoT application software (Lee and Lee, 2015).

Such a system could operate with the help of both people and artificial intelligence.

Transparent healthcare users' market: the evolutionary role of IoT technology is that allows the consumer access to resources such as network-based crowd. Consumers are creating personal markets and making their own healthcare decisions and are involved directly (B2C) with healthcare institutions.

Figure 3 Smart healthcare delivery model

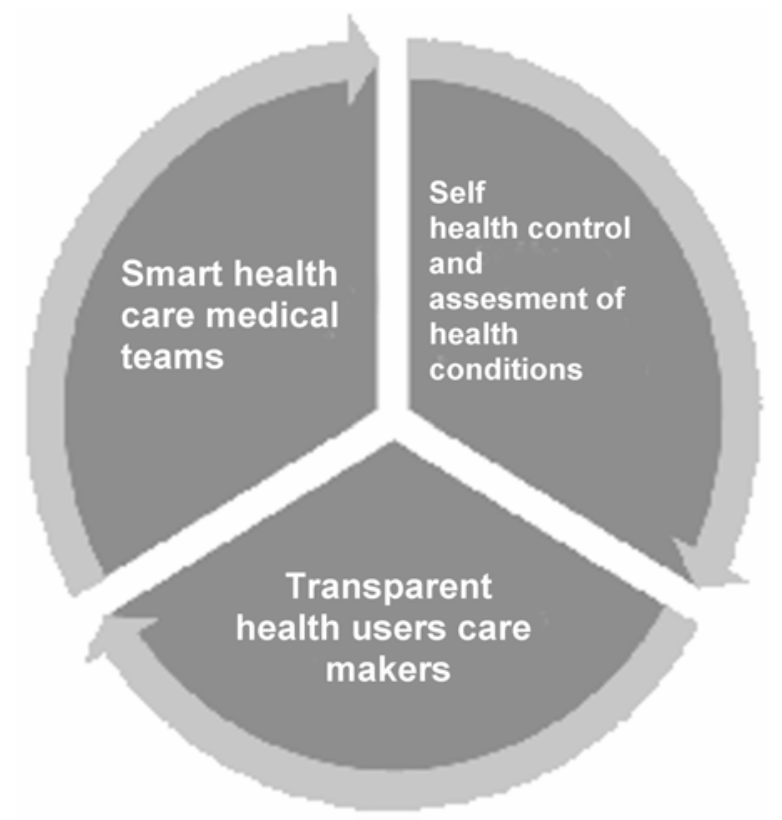

Source: Authors adaptation according to Pang et al. (2015) 
Smart care teams: such teams take care that consumers stay healthy and avoid expensive hospitalisation and urgent care interventions. Their toolkit includes big data, predictive modelling, personalised evidence-based medicine, and real-time biometric and clinical feedback.

\section{Research framework: patients view 'pro' and 'cons'}

Lee (2008) described the challenges to CPS, such as traffic control, automotive safety, and healthcare. Sha et al. (2009) considered CPS a new frontier for medicine.

Many of these scenarios have become, in effect, real: "the domain of healthcare and medicine includes national health information network, electronic patient record initiative, home care, operating room, etc., some of which are increasingly controlled by computer systems with hardware and software components, and are real-time systems with safety and timing requirements. Costanzo et al. (2016) also suggested the importance of mobile physical systems for healthcare.

A general process for reorganising medical work was thus needed, as discussed in previous sections; but what was the patients' point of view?

Haque et al., (2014) found some common feature for cyberphysical healthcare system:

1 software reliability

2 medical device interoperability

3 security and privacy

4 system feedback

5 architecture.

Unfortunately, patients are usually not able to specify desired attributes, and so a methodological support is necessary to identify them: using Kano's et al. (1984) model, this paper aims to clarify the quality requirements for cyberphysical health systems.

\subsection{Research methodology}

Kano's model is a qualitative approach capable of evaluating the relationship between the degree of fulfilment of a quality attribute and customer satisfaction with the quality attribute (Sauerwwin et al., 1996; Dominici and Palumbo, 2013). In this way, Kano (2001) has shown that some factors generate more satisfaction than others; thus, it is possible to classify the perceived quality in five ways:

- One-dimensional quality requirements $(O)$ : the increase in customer satisfaction due to their presence is proportional to the level of need fulfilment.

- Must-be quality requirements $(M)$ : if these they are not fulfilled, customer satisfaction will be very low, but their fulfilment will not significantly increase quality level.

- Attractive quality requirements (A): they have the greatest influence on customer satisfaction, but there is no dissatisfaction if they are not met. 
- Indifferent quality requirements (I): customers are not much interested in these.

- $\quad$ Reverse quality requirements $(R)$ : customers do not desire these and their presence evokes dissatisfaction.

In closing, Chaudha et al. (2011) added a sixth dimension indicating an illogical customer response or a question incorrectly phrased: questionable requirements (Q).

One of the main advantages of this model is that it provides a mindset in relation to how consumers evaluate a product or service (Ting and Chen, 2002). Indeed, compared to other, more rigorous, methods, such as principal component analysis or structural equations, the Kano model appears more flexible: in particular, Witell and Lögfren (2007) have recognised that the Kano model can identify priorities in relation to certain attributes that influence user choices and provide a classification of product characteristics, as well as the ability to highlight the importance of the attributes and the different ways in which they influence consumer satisfaction.

Other authors (Sauerwwin et al., 1996; Chaudha et al., 2011; Dominici et al., 2015) have instead investigated the capacity of the Kano model to provide directions that can be used in the design phase of the product or service, or to improve an existing function of satisfaction by the customer.

However, this model is not without its critics: its main limitation is its assumption of a linear relationship between the quality attributes and customer satisfaction. This assumption has been tested, and linear regression is not always statistically significant (Schvaneveldt et al., 1991; Dominici and Di Fatta, 2016). Nevertheless, even with a strictly linear relationship, it is widely accepted in the literature that there is a correlation between quality requirements and customer satisfaction (Ting and Chen, 2002; Tontini and Silveira, 2007; Witell and Lofgren, 2007; Dominici et al., 2015).

In order to implement the methodology, the following steps were performed:

Step 1 Choice of quality requirements

A focus group was developed, taking into account previous studies described in the literature review section and using five components:

1 software reliability

2 medical device interoperability

3 security and privacy

4 system feedback

5 architecture (Haque et al., 2014).

Section 3.2 describes the reasons behind this choice.

Step 2 Questionnaire

According to the Kano (2001) procedure, ten questions (two for each feature) were designed to evaluate both the positive aspect (the benefit associated with the presence of the feature) and the negative aspect (the disadvantage associated with the lack of the feature). The questionnaire will be described in more detail in Sections 3.3 and 3.4. 
Step 3 Sample selection

We selected 150 candidates through a spontaneous application process, who all possessed the following requirements: they had had at least one interaction with cyberphysical healthcare system (CPS) in the last year, and they intended to have at least one interaction with CPS in the next year.

The application form was open from September to December 2016, when we reached the target of 150 respondents satisfying the requirements.

Step 4 Data collection

The respondents were asked to indicate their agreement with the statements by checking one of five response categories on the Likert scale: strongly disagree, disagree, neither agree nor disagree, agree, and strongly agree. Section 4 presents the results.

\subsection{Quality requirements for cyberphysical health systems}

This section deals in more depth with the above-mentioned features. They are consistent with the previous research of Lee et al. (2012), which studied the main technical challenges for CPS health systems, such as software, device interoperability, security, and privacy

1 Software reliability. Lee and Sokolsky (2010) about trends in the development and use of high-confidence medical cyberphysical systems (MCPS), finding increased reliance on software to deliver new functionality. Software is a crucial part of cyberphysical health systems and medical devices: the design, construction, and verification of CPS pose a multitude of technical challenges (Rajkumar et al., 2010).

The point is that device functionality is ensured through software, and therefore the safety and efficiency of the system rely on that software which is the link between the medical device and the patient.

2 Medical device interoperability. Multiple medical devices may have different communication interfaces, but they must work as system and symbiotically. The system should integrate heterogeneous medical devices in a safe, secured, and certified manner.

In this regard, Lesh et al. (2007) argued that medical device interoperability is an almost nonexistent feature of medical devices. In order to fill this gap, Asare et al. (2012) described an open-source standards-based platform for interoperable medical device connectivity.

3 Security and privacy. Ensuring the safety of the collected data is the most critical task. Sweeney (2002, p.4) suggested that "while access control and authentication protections can safeguard against direct disclosures, they do not address disclosures based on inferences that can be drawn from released data", meaning that computer security is not equal to the demands of privacy protection. 
Thus according to Farhangi (2016), cybersecurity vulnerability still remains a problem. Indeed, unlawful use patient data can damage a firm's reputation and, consequently, lead to a loss of trust by users.

4 System feedback. CPS in healthcare depicts a feedback system via a smart alarm system. Alarm systems are of paramount importance to notify the caregiver of any possible illness or emergency situation.

However, the alarm system needs to address some challenges, such as types of physiological parameter, system complexity, and implementation ability (Baheti and Gill, 2011). According to Haque et al. (2014) the feedback system needs to be simple to use and comprehensible for patients. Complexity must not hinder efficient use by patients and caregivers.

5 Architecture. Prototype architecture is useful for testing, evaluating, and developing CPS, which includes healthcare devices. The appropriateness of CPS in healthcare relies on the right architecture. The software is certainly important, but the system may not work properly without the proper hardware.

Wang et al. (2000) proposed an architecture composed of three main components: namely a communication core, a computation core, and a resource scheduling and management core. This structure is also supported by Haque et al. (2014).

\subsection{Kano questionnaire}

In the light of this reasoning and also following (Haque et al., 2014), we developed the Kano questionnaire on the basis of the five factors:

1 software reliability

2 medical device interoperability

3 security and privacy

4 system feedback

5 architecture.

Concluding this section, the proposed framework is built upon a qualitative methodology useful for measuring user perceived quality and satisfaction in cyberphysical healthcare systems. Thus, following the Kano model, it is possible to classify the factors and to understand which factors are the most attractive to users. In this way, managers can receive practical implications for allocating corporate resources to the factors most relevant to the user perceived quality and the customer satisfaction. 
Table 2 Kano questionnaire for patients

\begin{tabular}{llllll}
\hline Kano questionnaire & \multicolumn{1}{c}{} \\
\hline $\begin{array}{l}\text { The respondent is asked to describe his or her agreement by checking one of five options: (1) } \\
\text { strongly disagree, (2) disagree, (3) neither agree nor disagree, (4) agree, (5) }\end{array}$ strongly agree. \\
\hline Software reliability is useful in cyberphysical health systems. & 1 & 2 & 3 & 4 & 5 \\
I do not care about software reliability in cyberphysical health systems. & 1 & 2 & 3 & 4 & 5 \\
Pay attention to medical devices which interoperate with each other. & 1 & 2 & 3 & 4 & 5 \\
Medical devices interoperability is not relevant. & 1 & 2 & 3 & 4 & 5 \\
Security and privacy issues in cyberphysical health systems make me & 1 & 2 & 3 & 4 & 5 \\
feel safe. & & & & & \\
I don't pay any attention to security and privacy policies. & 1 & 2 & 3 & 4 & 5 \\
I expect feedback from the system. & 1 & 2 & 3 & 4 & 5 \\
System feedback and notifications annoy me. & 1 & 2 & 3 & 4 & 5 \\
The architecture of a system can make it easy to use. & 1 & 2 & 3 & 4 & 5 \\
I don't care about the architecture used in cyberphysical health systems.
\end{tabular}

\section{Results and discussions}

The following table describes the findings of the analysis of the data from the Kano questionnaire.

Medical device interoperability and architecture were found to be attractive quality requirements; system feedback was found to be one dimensional. These are the most relevant features for the customer satisfaction index (CSI) (Berger et al., 1993; Tarasewich et al., 2002), which will be considered later.

Furthermore, it is also important to note that software reliability was found to be indifferent from the patient's point of view, which instead considered security and privacy to be a must-be requirement for cyberphysical healthcare system.

Table 3 Kano questionnaire results (see online version for colours)

\begin{tabular}{|c|c|c|c|c|c|c|c|c|c|c|}
\hline \multirow[b]{2}{*}{ Attr. } & \multicolumn{2}{|c|}{$\begin{array}{l}\text { (1) Software } \\
\text { reliability }\end{array}$} & \multicolumn{2}{|c|}{$\begin{array}{l}\text { (2) Medical device } \\
\text { interoperability }\end{array}$} & \multicolumn{2}{|c|}{$\begin{array}{l}\text { (3) Security } \\
\text { and privacy }\end{array}$} & \multicolumn{2}{|c|}{$\begin{array}{l}\text { (4) System } \\
\text { feedback }\end{array}$} & \multicolumn{2}{|c|}{ (5) Architecture } \\
\hline & Freq. & Perc. & Freq. & Perc. & Freq. & Perc. & Freq. & Perc. & Freq. & Perc. \\
\hline $\mathrm{O}$ & 32 & $21.3 \%$ & 44 & $29.3 \%$ & 30 & $20.0 \%$ & 63 & $42.0 \%$ & 43 & $28.7 \%$ \\
\hline M & 34 & $22.7 \%$ & 8 & $5.3 \%$ & 65 & $43.3 \%$ & 23 & $15.3 \%$ & 21 & $14.0 \%$ \\
\hline A & 20 & $13.3 \%$ & 59 & $39.3 \%$ & 31 & $20.7 \%$ & 41 & $27.3 \%$ & 58 & $38.7 \%$ \\
\hline I & 64 & $42.7 \%$ & 39 & $26.0 \%$ & 23 & $15.3 \%$ & 23 & $15.3 \%$ & 26 & $17.3 \%$ \\
\hline $\mathrm{R}$ & 0 & $0.0 \%$ & 0 & $0.0 \%$ & 1 & $0.7 \%$ & 0 & $0.0 \%$ & 2 & $1.3 \%$ \\
\hline Tot. & 150 & 1 & 150 & 1 & 150 & 1 & 150 & 1 & 150 & 1 \\
\hline
\end{tabular}

Notes: O: one-dimensional quality requirement, M: must-be quality requirement,

A: attractive quality requirement, I: indifferent quality requirement,

$\mathrm{R}$ : reverse quality requirement. 
The above-mentioned CSI is an indicator that quantifies the ability of each requirement to satisfy customer needs (Berger et al., 1993). It is computed as follows:

$$
C S I=\frac{(A+O)}{(A+O+M+I)}
$$

The CSI ranges from 0 to 1 ; the closer to 1 it is, the greater the impact on customer satisfaction. This research also considers the negative side of quality: the customer dissatisfaction index (CDI) indicates the degree of dissatisfaction resulting from the non-fulfilment of a need, which therefore takes on a negative connotation in for the customer experience (Berger et al., 1993; Rust and Oliver, 2000).

$$
C D I=-\frac{(M+O)}{(A+O+M+I)}
$$

This index ranges between -1 and 0 ; the closer it is to -1 , the greater the negative impact on the level of user satisfaction, thus generating dissatisfaction. The following table presents the calculated values of CSI and CDI:

Table 4 Customer satisfaction and dissatisfaction indices

\begin{tabular}{lc}
\hline Requirements & $C S I$ \\
\hline (O) System feedback & 0.693 \\
(A) Medical device interoperability & 0.687 \\
(A) Architecture & 0.639 \\
(M) Security and privacy & 0.409 \\
(I) Software reliability & 0.347 \\
\hline Requirements & $C D I$ \\
\hline (M) Security and privacy & -0.638 \\
(O) System feedback & -0.573 \\
(I) Software reliability & -0.440 \\
(A) Architecture & -0.405 \\
(A) Medical device interoperability & -0.347 \\
\hline
\end{tabular}

Attractive requirement, such as architecture and medical device interoperability have high values for CSI and low scores for CDI: this is consistent with the Kano (1995) model. Instead, system feedback (a one-dimensional requirement) is characterised by high scores for both indices: this means that it is a critical requirement affecting customer satisfaction and dissatisfaction in CPS. In other words, given limited resources, decision makers should allocate their effort to improve system feedback mechanisms.

Furthermore, must-be requirements, such as security and privacy, do not particularly increase customer satisfaction (CSI score is low); however, this requirement has a great impact on dissatisfaction: this means that patients expect a 'minimum level' of security and privacy. Once this value is reached, further improvements do not generate further satisfaction; however, if this threshold is not reached, the dissatisfaction is very high: the CDI score is the highest, at -0.638 .

The final consideration is about software reliability, which is considered an indifferent requirement: ignoring this would be a mistake, because it affects both 
customer satisfaction and dissatisfaction, but in a mild way. However, it is important to use the Kano model in order to identify the hierarchy in requirements considered most important, according to user perceptions. In this way, following the Kano results, the decision makers may decide to allocate resources to the requirements than can generate greater customer satisfaction.

\section{Conclusions}

Industry 4.0 is increased competitiveness through smart equipment, making use of information about high-wage locations, demographic changes, resources, energy efficiency, and urban production. Cities and their services and systems are smarter now than in previous decades. Industry 4.0 allows smart cities to take a new approach to digital sustainability. Sustainability and resource efficiency are increasing in the focus of the design of smart cities. Smart technologies monitor and archive large amounts of data about human behaviour.

Given this framework, knowledge management 4.0 could be an opportunity. One case of monitoring human behaviour presents a smart home healthcare system, where embedded computers and networks monitor and control physical processes, with feedback loops allowing physical processes to affect computations, and vice versa. All information is stored in the cloud and digital-health companies enable the exchange of health data.

Users of the system need to be aware that data from smart systems will be used for creation of a new economic services and business opportunities. Public agencies, institutions (e.g., national health institutions) and companies (e.g., insurance companies, healthcare providers, and pharmaceutical companies) will benefit from access to data for the appropriate purposes. The data will be used according to the precepts of a new smart technological era. Healthcare institutions are moving towards a new framework that of the service provider.

A customer evaluation of the smartest healthcare system is important for all stakeholders that will play a role in the implementation of this system. To this end, we developed a Kano questionnaire on the five most important factors affecting customer decisions to purchase such a system:

1 software reliability

2 medical device interoperability

3 security and privacy

4 system feedback

5 architect.

The results show that attractive requirements, such as architecture and medical device interoperability, have high values for CSI and low scores for CDI. On the other hand, system feedback (a one-dimensional requirement) is characterised by high scores in both indices: this means that this is a critical requirement affecting customer satisfaction and dissatisfaction in CPS. 
A piece of crucial information for the development of the smartest health system is that patients expect a 'minimum level' of security and privacy. This requirement has a great impact on customer dissatisfaction. Software reliability is considered an indifferent requirement, which mildly affects customer satisfaction and dissatisfaction.

\section{References}

Asare, P., Cong, D., Vattam, S.G., Kim, B., King, A., Sokolsky, O. and Mullen-Fortino, M. (2012) 'The medical device dongle: an open-source standards-based platform for interoperable medical device connectivity', in Proceedings of the 2nd ACM SIGHIT International Health Informatics Symposium, ACM, January, pp.667-672.

Aue, G., Biesdorf, S. and Henke, N. (2016) How Healthcare System Can Become Digital-Health Leaders, McKinsey [online] http://www.mckinsey.com/industries/healthcare-systems-andservices/our-insights/how-healthcare-systems-can-become-digital-health-leaders (accessed 26 July 2016).

Baheti, R. and Gill, H. (2011) 'Cyber-physical systems', The Impact of Control Technology, Vol. 12, No. 1, pp.161-166.

Balta-Ozkan, N., Boteler, B. and Amerighi, O. (2014) 'European smart home market development: public views on technical and economic aspects across the United Kingdom, Germany and Italy', Energy Research \& Social Science, Vol. 3, No. 1, pp.65-77.

Berger, C., Blauth, R., Boger, D., Bolster, C., Burchill, G., DuMouchel, W. and Timko, M. (1993) 'Kano's methods for understanding customer-defined quality', Center for Quality Management Journal, Vol. 2, No. 4, pp.3-35.

Calenti-Millan, J. and Maseda, A. (2011) 'Elderly people, disability, dependence and new technologies', in Pereira, J. (Ed.): Handbook of Research on Personal Autonomy Technologies and Disability Informatics, pp.36-45, IGI Global, Hershey.

Chan, M., Campo, E., Esteve, D. and Fourniols, J. (2009) 'Smart homes - current features and future perspectives', Maturitas, Vol. 64, No. 1, pp.90-97.

Chaudha, A., Jain, R., Singh, A.R. and Mishra, P.K. (2011) 'Integration of Kano's model into quality function deployment (QFD)', The International Journal of Advanced Manufacturing Technology, Vol. 53, No. 5, pp.689-698.

Cooper, J. and James, A. (2009) 'Challenges for database management in the internet of things', IETE Tech Rev, Vol. 26, No. 5, pp.320-329.

Davis, R. (2014) Older People in Europe: EU Policies and Programmes, European parliamentary research service, Strasbourg.

Di Fatta, D., Caputo, F., Evangelista, F. and Dominici, G. (2016) 'Small world theory and the world wide web: linking small world properties and website centrality', International Journal of Markets and Business Systems, Vol. 2, No. 2, pp.126-140.

Di Fatta, D., Cupido, F. and Dominici, G. (2017) 'The value of a network in the digital era: insights about doctor chat case study', International Journal of Electronic Marketing and Retailing, Vol. 8, No. 4, pp.301-215.

Dominici, G. and Di Fatta, D. (2016) 'Quali sono le determinanti della web quality di un e-commerce? Applicazione del modello di Kano al caso scalia group', Proceeding of XXVIII Sinergie Annual Conference, Udine, Italy, 9-10 June.

Dominici, G. and Palumbo, F. (2013) 'How to build an e-learning product: factors for student/customer satisfaction', Business Horizons, Vol. 56, No. 1, pp.87-96.

Dominici, G., Palumbo, F. and Basile, G. (2015) 'The drivers of customer satisfaction for academic library services: managerial hints from an empirical study on two Italian university libraries using the Kano model', International Journal of Management in Education, Vol. 9, No. 3, pp.267-289. 
Dominici, G., Roblek, V., Abbate, T. and Tani, M. (2016) 'Click and drive: consumer attitude to product development: towards future transformations of the driving experience', Business Process Management Journal, Vol. 22, No. 2, pp.420-434.

Executive Roundtable on Cyber-physical Systems (2013) Strategic Vision and Business Drivers for 21 st Century Cyber-Physical Systems [online] http://www.nist.gov/el/upload/Exec-Round table-SumReport-Final-1-30-13.pdf (accessed 26 June 2016).

Farhangi, H. (2016) 'Cyber-security vulnerabilities: an impediment against further development of smart grid', in Smart Grids from a Global Perspective, pp.77-93, Springer International Publishing.

Gill, H. (2010) Cyber-Physical Systems: Beyond ES, SNs, and SCADA Presentation in the Trusted Computing in Embedded Systems (TCES) Workshop [online] http://repository.cmu.edu/cgi/ viewcontent.cgi?article $=1724 \&$ context $=$ sei (accessed 26 June 2016).

Gunes, V., Peter, S., Givargis, T. and Vahid, F. (2014) 'A survey on concepts, applications, and challenges in cyber-physical systems, KSII Transactions on Internet and Information Systems, Vol. 8, No. 12, pp.4242-4268.

Haque, S.A., Aziz, S.M. and Rahman, M. (2014) 'Review of cyber-physical system in healthcare', International Journal of Distributed Sensor Networks, Vol. 4, No. 10, pp.115-127, DOI: 10. $1155 / 2014 / 217415$.

Haque, S.A., Aziz, S.M. and Rahman, M. (2014) 'Review of cyber-physical system in healthcare', International Journal of Distributed Sensor Networks, Vol. 10, No. 4, pp.217-241.

Kano, N. (1995) Upsizing the Organization by Attractive Quality Creation, in Total Quality Management, pp.60-72, Springer, Dordrecht.

Kano, N. (2001) 'Life cycle and creation of attractive quality', 4th International QMOD Conferencem, Linkopings Universitet, Sweden.

Kano, N., Seraku, N., Takahashi, F. and Tsuji, S. (1984) 'Attractive and normal quality', Quality, Vol. 14, No. 2, pp.39-48.

Lee, E.A. (2008) 'Cyber physical systems: design challenges, Proc. of 11th IEEE International Symposium on Object Oriented Real-Time Distributed Computing, pp.363-369.

Lee, I. and Lee, K. (2015) 'The IoT (IoT): applications, investments, and challenges for enterprises', Business Horizon, Vol. 58, No. 4, pp.431-440.

Lee, I. and Sokolsky, O. (2010) 'Medical cyber physical systems', in 47th ACM/IEEE on Design Automation Conference (DAC), IEEE, June, pp.743-748.

Lee, I., Sokolsky, O., Chen, S., Hatcliff, J., Jee, E., Kim, B. and Venkatasubramanian, K.K. (2012) 'Challenges and research directions in medical cyber-physical systems', Proceedings of the IEEE, Vol. 100, No. 1, pp.75-90.

Luor, T.T., Lu, H.P., Yu, H. and Lu, Y. (2015) 'Exploring the critical quality attributes and models of smart homes', Maturitas, Vol. 82, No. 4, pp.377-386.

Man, L.C.K., Na, C.M. and Kit, N.C. (2015) 'IoT-based asset management system for healthcare-related industries', Int. J. Eng. Bus. Man., Vol. 7 [online] http://cdn.intechopen. com/pdfs-wm/49565.pdf (accessed 26 June 2016).

Marwedel, P. (2010) Embedded System Design, Springer, Cham.

Möller, D.P. (2016) Introduction to Cyber-Physical Systems, in Guide to Computing Fundamentals in Cyber-Physical Systems, pp.81-139, Springer International Publishing, Cham.

Mosconi, F. (2015) The New European Industrial Policy: Global Competitiveness and the Manufacturing Renaissance, Routledge, London.

Pang, Z., Zheng, L., Tian, J., Walter-Kao, S., Dubrova, E. and Chen, Q. (2015) 'Design of a terminal solution for integration of in-home health care devices and services towards the internet-of-things', Ent. Info. Sys., Vol. 9, No. 1, pp.86-116.

Rajkumar, R., Lee, I., Sha, L. and Stankovic, J. (2010) 'Cyber-physical systems: the next computing revolution', Proc. of 47th IEEE/ACM Design Automation Conference, pp.731-736. 
Roblek, V., Meško, M. and Krapež, A. (2016) 'A complex view of industry 4.0', Sage Open, Vol. 6, No. 2, pp.1-10.

Rust, R.T. and Oliver, R.L. (2000) 'Should we delight the customer?', Journal of the Academy of Marketing Science, Vol. 28, No. 1, pp.86-94.

Sauerwwin, E., Bailom, F., Matzler, K. and Hinterhuber, H.H. (1996) 'The Kano model: how to delight your customers', Journal of Product \& Brand Management, Vol. 5, No. 2, pp.6-18.

Schvaneveldt, S.J., Enkawa, T. and Miyakawa, M. (1991) 'Consumer evaluation perspectives of service quality: evaluation factors and two-way model of quality', Total Quality Management, Vol. 2, No. 2, pp.149-162.

Sedlar, U., Volk, M. and Bester, J. (2015) 'An approach to designing and developing digital health solutions', Elektrotehniski Vestnik, Vol. 82, No. 3, pp.130-137.

Sha, L., Gopalakrishnan, S., Liu, X. and Wang, Q. (2009) 'Cyber-physical systems: a new frontier', Machine Learn-ing in Cyber Trust, pp.3-13.

Sweeney, L. (2002) 'k-anonymity: a model for protecting privacy', International Journal of Uncertainty, Fuzziness and Knowledge-Based Systems, Vol. 10, No. 5, pp.557-570.

Tarasewich, P., Nickerson, R.C. and Warkentin, M. (2002) 'Issues in mobile e-commerce', Communications of the Association for Information Systems, Vol. 8, No. 1, p.3.

Ting, S.C. and Chen, C.N. (2002) 'The asymmetrical and non-linear effects of store quality attributes on customer satisfaction', Total Quality Management, Vol. 13, No. 4, pp.547-569.

Toledo Parra, C.A., Gamboa Sarmiento, S.C. and Di Fatta, D. (2017) 'Studying university as social systems using the viable system model: mApp and semantic web technologies at the industrial University of Santander', Journal of Organisational Transformation \& Social Change, Vol. 14, No. 1, pp.56-77.

Tontini, G. and Silveira, A. (2007) 'Identification of satisfaction attributes using competitive analysis of the improvement gap', International Journal of Operations \& Production Management, Vol. 27, No. 5, pp.482-500.

Victor, C.R. (2013) Old Age in Modern Society: a Textbook of Social Gerontology, Springer, London.

Wang, H.J., Raman, B., Chuah, C.N., Biswas, R., Gummadi, R., Hohlt, B. and Subraimanian, L. (2000) 'ICEBERG: an internet core network architecture for integrated communications', IEEE Personal Communications, Vol. 7, No. 4, pp.10-19.

Witell, L. and Logfren, M. (2007) 'Classification of quality attributes', Managing Service Quality, Vol. 17, No. 1, pp.54-73.

Yolles, M. and Di Fatta, D. (2017a) 'Modelling identity types through agency: part 1 defragmenting identity theory', Kybernetes, Vol. 46, No. 6, pp.1068-1084.

Yolles, M. and Di Fatta, D. (2017b) 'Modelling identity types through agency: part 2 connecting personality and identity through agency theory', Kybernetes, Vol. 46, No. 6, pp.1112-1130 [online] https://doi.org/10.1108/K-04-2017-0123. 